\title{
Evidence for Acute Stimulation of Fibrinogen Production by Glucagon in Humans
}

\author{
P. Tessari, E. Iori, M. Vettore, M. Zanetti, E. Kiwanuka, G. Davanzo, and R. Barazzoni
}

\begin{abstract}
Fibrinogen, an acute-phase protein, and glucagon, a stress hormone, are often elevated in many conditions of physical and metabolic stress, including uncontrolled diabetes. However, the possible mechanisms for this association are poorly known. We have studied the acute effects of selective hyperglucagonemia (raised from $\sim 200$ to $\sim 350 \mathrm{pg} / \mathrm{ml}$ for $3 \mathrm{~h}$ ) on fibrinogen fractional secretion rate (FSR) in eight normal subjects during infusion of somatostatin and replacement doses of insulin, glucagon, and growth hormone. Fibrinogen FSR was evaluated by precursor-product relationships using either Phe $(n=8)$ or Leu $(n=2)$ tracers. Hyperglucagonemia did not change either plasma Phe or Tyr specific activity. After hyperglucagonemia, fibrinogen FSR increased by $\sim 65 \%$ (from $12.9 \pm 3.6$ to $21.5 \pm 6.1 \%$ per day, $P<0.025$ ) using plasma $P$ he specific activity as the precursor pool. FSR increased by $\sim 80 \%$ (from 16.6 \pm 4.8 to $29.4 \pm 8.8 \%$ per day, $P<0.025$ ) if plasma $P$ he specific activity was corrected for the ketoisocaproate/Leu enrichment (or specific activity) ratio to obtain an approximate estimate of intrahepatic Phe specific activity. FSR increased by $\sim 60 \%$ when using plasma Tyr specific activity as precursor pool $(n=8)(P$ $<0.05$ ), as well as when using the Leu tracer precursorproduct relationship $(n=2)$. In conclusion, selective hyperglucagonemia for $\sim 3 \mathrm{~h}$ acutely stimulated fibrinogen FSR using a Phe tracer method. Thus, glucagon may be involved in the increase of fibrinogen concentration and FSR observed under stressed or pathologic conditions. Diabetes 46:1368-1371, 1997
\end{abstract}

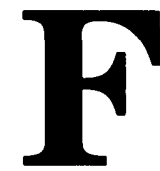

ibrinogen is an acute-phase protein (1) that is increased in uncontrolled diabetes, vascular disease, and smoking and in many conditions of physical and metabolic stress (2-6). Its plasma concentration has been recognized as a strong and independent cardiovascular risk factor (7). Nevertheless, the mechanisms and the factors that regulate fibrinogen synthesis in vivo are poorly understood. In humans, fibrinogen fractional secretion rate (FSR) was increased by acute insulin deficiency in IDDM (8), while it was decreased by short-term insulin infusion in both normal subjects and subjects with $\operatorname{IDDM}(8,9)$.

From the Department of Metabolic Diseases, University of Padua, Padua, Italy.

Address correspondence and reprint requests to Dr. Paolo Tessari, Cattedra di Malattie del Metabolismo, Department of Clinical and Experimental Medicine, Policlinico Universitario, Via Giustiniani 2, 35128 Padua, Italy.

Received for publication 10 December 1996 and accepted in revised form 12 May 1997.

FSR, fractional secretion rate; HPLC, high-performance liquid chromatography; KIC, $\alpha$-ketoisocaproate; MPE, mole percent enrichment.
Besides these scarce data, however, the role of other hormonal or metabolic factors in regulating fibrinogen FSR in vivo is largely unknown. In many conditions in which fibrinogen concentration is elevated, including uncontrolled diabetes (10), the concentration of glucagon is also increased. Since glucagon is a stress hormone (11), it might be involved in the synthesis of acute-phase reactants. Thus, it is interesting to investigate whether there is a causal association between increments of glucagon concentrations and fibrinogen FSR in vivo.

The aim of this study was therefore to evaluate whether an isolated and acute increase of glucagon concentration, achieved by means of an exogenous infusion while maintaining insulin and growth hormone concentrations at baseline, is able to stimulate fibrinogen FSR in normal volunteers in the postabsorptive state.

\section{RESEARCH DESIGN AND METHODS}

Isotopes. $\mathrm{L}-\left[1-{ }^{14} \mathrm{C}\right]$ phenylalanine $(\sim 55 \mathrm{mCi} / \mathrm{mmol})\left(\left[{ }^{14} \mathrm{C}\right] \mathrm{Phe}\right), \mathrm{L}-\left[2,6-{ }^{3} \mathrm{H}\right]$ phenylalanine $(\sim 50 \mathrm{Ci} / \mathrm{mmol})\left(\left[{ }^{3} \mathrm{H}\right] \mathrm{Phe}\right)$, and $\mathrm{L}-\left[1-^{14} \mathrm{C}\right]$ leucine $(\sim 50 \mathrm{mCi} / \mathrm{mmol})\left(\left[{ }^{14} \mathrm{C}\right] \mathrm{Leu}\right)$ were purchased from Amersham (Buckinghamshire, U.K.). $\mathrm{L}-\left[5,5,5{ }^{-}{ }^{-} \mathrm{H}\right]$ leucine $\left(\left[{ }^{2} \mathrm{H}_{3} \mathrm{Leu}\right)(>98 \%\right.$ purity) was purchased from Tracer Technologies (Somerville, MA). All isotopes were proven to be sterile and pyrogen-free before use.

Experimental design. Eight healthy male volunteers (age $25 \pm 1$ years, BMI 22.6 $\pm 1.3 \mathrm{~kg} / \mathrm{m}^{2}$ ) were studied after an overnight fast. The aims of the study were explained in detail to each subject, who then gave informed written consent. The protocol was approved by the competent local authority (i.e., the director of the department) because at the time of the study no ethical committee had been established at our university. The study was performed according to the recommendations of the radiation safety officer. Each subject had been adapted to a weightmaintaining diet containing $\sim 50 \%$ carbohydrate, $\sim 20 \%$ protein, and $\sim 30 \%$ fat for at least 1 month before the study. The study protocol has been described in detail elsewhere (12). Six of the eight subjects reported on here were subjects in that study. Briefly, at 7:30 A.M., one polyethylene catheter was placed in an antecubital vein for isotope and hormone infusion, and another catheter was placed retrogradely in a dorsal vein of the opposite hand, which was maintained at $55^{\circ} \mathrm{C}$ for arterialized venous blood sampling. At 8:00 A.M., intravenous infusions of somatostatin (Stilamin, Serono, Rome, Italy; infusion rate $250-400 \mu \mathrm{g} / \mathrm{h}$ ) and of replacement doses of glucagon (Novo, Bagswaert, Denmark; infusion rate $1 \mathrm{ng}$. $\mathrm{kg}^{-1} \cdot \mathrm{min}^{-1}$ ), regular insulin (Actrapid, Novo; infusion rate $0.07 \mathrm{U} \cdot \mathrm{kg}^{-1} \cdot \mathrm{min}^{-1}$ ), and human recombinant growth hormone (Humatrope, Lilly Italia, Florence, Italy; infusion rate $9 \mathrm{ng} \cdot \mathrm{kg}^{-1} \cdot \mathrm{min}^{-1}$ ) were started to suppress endogenous hormone secretion and to maintain levels near baseline values. Each hormone was dissolved in saline containing $1 \%$ human albumin to prevent its absorption into the plastic syringes and catheters.

At 8:00 A.M. (time $-180 \mathrm{~min}$ ), primed continuous infusions of either $\left[{ }^{[4} \mathrm{C}\right] \mathrm{Phe}$ and of $\left[{ }^{2} \mathrm{H}_{3}\right]$ Leu $(n=7)$ or $\left[{ }^{3} \mathrm{H}\right]$ Phe and $\left[{ }^{14} \mathrm{C}\right]$ Leu $(n=2)$ were initiated by means of a calibrated pump (Harvard Apparatus, South Natick, MA). The rate of radioactive Phe infusion $(n=8)$ (i.e., of the combined ${ }^{14} \mathrm{C}$ and ${ }^{3} \mathrm{H}$ tracers) was $~ 5,560$ $\mathrm{dpm} \cdot \mathrm{kg}^{-1} \cdot \mathrm{min}^{-1}$, that of $\left[{ }^{2} \mathrm{H}_{3}\right]$ Leu $(n=6)$ was $0.052 \pm 0.002 \mu \mathrm{mol} \cdot \mathrm{kg}^{-1} \cdot \mathrm{min}^{-1}$, and that of $\left[{ }^{14} \mathrm{C}\right] \mathrm{Leu}(n=2)$ was $~ 5,400 \mathrm{dpm} \cdot \mathrm{kg}^{-1} \cdot \mathrm{min}^{-1}$. Isotope priming doses were equivalent to 30 times the continuous infusion rates per minute. Blood samples were taken every $30 \mathrm{~min}$ during the first $150 \mathrm{~min}$ (time -180 to $-30 \mathrm{~min}$ ) and thereafter every $10 \mathrm{~min}$ between -30 and $0 \mathrm{~min}$ (defined as basal period). After the 120th minute (time - $-60 \mathrm{~min}$ ), steady state was achieved in plasma substrate and isotope concentrations, as shown previously (12). Also, the -60 -min plasma Phe and Leu concentrations, specific activities, and enrichments were not significantly different from the subsequent ( -30 to $0 \mathrm{~min}$ ) values. 
At $0 \mathrm{~min}$, a freshly prepared glucagon solution was infused at the rate of $\sim 3$ $\mathrm{ng} \cdot \mathrm{kg}^{-1} \cdot \mathrm{min}^{-1}$ for an additional $3 \mathrm{~h}$ while replacement infusions of other hormones were maintained. Blood samples were again taken every $30 \mathrm{~min}$ until time $150 \mathrm{~min}$ and then every $10 \mathrm{~min}$ in the last $30 \mathrm{~min}$ of study (defined as the glucagon period). A new steady state in substrate and isotope concentrations was attained by the 120 th minute of glucagon infusion (data not shown).

Analytical methods. Plasma Phe (13) and Leu (14) concentrations and specific activities, as well as $\alpha$-ketoisocaproate (KIC) specific activity (14), were measured by high-performance liquid chromatography (HPLC) as referenced. Plasma $\left[{ }^{14} \mathrm{C}\right]$ Tyr specific activity was determined as described by Tessari et al. (15). Plasma $\left[{ }^{2} \mathrm{H}_{3}\right]$ Leu and $\left[{ }^{2} \mathrm{H}_{3}\right] \mathrm{KIC}$ mole percent enrichments (MPEs) were measured as $t$-butyldimethylsilyl derivatives (16) by gas chromatography-mass spectrometry (model 5988; Hewlett-Packard), using a capillary column and electronimpact ionization. Plasma insulin, C-peptide, glucagon, and growth hormone concentrations were determined by radioimmunoassay as previously described (12). Plasma glucose was measured using a Beckman Glucose Analyzer 2 (Beckman Instruments, Fullerton, CA).

To isolate fibrinogen from other plasma proteins, $100 \mu \mathrm{l}$ of $1 \mathrm{~mol} / \mathrm{CaCl}_{2}$ and $100 \mathrm{\mu l}$ thrombin (corresponding to $10 \mathrm{IU}$ ) were added to $2 \mathrm{ml}$ of plasma to transform fibrinogen into fibrin (17). The sample was then incubated for $1 \mathrm{~h}$ at room temperature. The fibrin clot was removed with a Pasteur pipette, layered into filter paper, and gently washed with deionized water to remove any residual contaminating plasma. The fibrin filament was then placed into a glass vial, resuspended with $3 \mathrm{ml}$ of $4 \mathrm{~N} \mathrm{HCl}$, and incubated for $72 \mathrm{~h}$ in airtight vials at $110^{\circ} \mathrm{C}$ for hydrolysis. The resulting hydrolyzed amino acids were filtered before being applied to cation exchange Ag $50 \times 8$ columns. Removal of the amino acids from the column was accomplished by means of $1 \times 6 \mathrm{ml}$ of $25 \%(\mathrm{vol} / \mathrm{vol})$ ammonium hydroxide. After lyophilization, fibrinogen-derived Phe specific activity was then determined by HPLC, using a $0.02 \mathrm{~mol} / \mathrm{s}$ sodium phosphate buffer at $\mathrm{pH} 3$ and ultraviolet detection at $256 \mathrm{~nm}$. In the two subjects in whom the $\left[{ }^{14} \mathrm{C}\right]$ Leu was infused, fibrinogen-derived Leu specific activity was determined by HPLC as described by Horber et al. (17).

Calculations. The FSR of fibrinogen was calculated using the samples drawn between -60 and $0 \mathrm{~min}$ (basal period) and between 120 and $180 \mathrm{~min}$ (glucagon infusion period), i.e., when plasma Phe and Tyr specific activities, as well as plasma Leu and $\mathrm{KIC}^{2} \mathrm{H}_{3}$ enrichments, were at near-steady state.

FSR was calculated using a linear relationship as follows:

$$
\text { FSR (\% of pool synthesized per day) }=\frac{\mathrm{SA}_{t(2)}-\mathrm{SA}_{t(1)}}{\frac{t(2)-t(1)}{\mathrm{SA}_{\text {precursor }}}} \times 1,440 \times 100
$$

where $\mathrm{SA}_{t(2)}$ and $\mathrm{SA}_{t(1)}$ are flbrinogen-bound radioactive Phe specific activities (in disintegrations per minute per nanomole) at time points $t_{(2)}$ and $t_{(1)}$ respectively; $\mathrm{SA}_{\text {precursor }}$ is plasma specific activity at near-steady state of the chosen precursor pool (see below); the factor 1,440 is used to express data per 1 day (to $24 \mathrm{~h}$, i.e., 1,440 $\mathrm{min}$ ); and 100 is to convert FSR to a percentage.

Using the Phe tracers, we used three different options as $\mathrm{SA}_{\text {precursor: }}$ 1) plasma Phe specific activity $\left({ }^{14} \mathrm{C}\right.$ specific activity in six subjects; ${ }^{3} \mathrm{H}$ specific activity in two); 2) estimated intracellular Phe specific activity; and 3) plasma Tyr specific activity $\left({ }^{14} \mathrm{C}\right.$ specific activity in six subjects; ${ }^{3} \mathrm{H}$ specific activity in two). Estimated intracellular Phe specific activity was calculated by multiplying the actual plasma Phe specific activity times the ratio of KIC to Leu ${ }^{2} \mathrm{H}_{3}$ MPE $(n=6)$ or KIC to Leu ${ }^{14} \mathrm{C}$ speciffc activity $(n=2)(18)$. With this calculation, it is assumed that the ratio between the (unknown) intracellular and the plasma Phe specific activity is the same as that between plasma KIC (i.e., a marker of intracellular Leu labeling) and plasma Leu specific activity (18). The third calculation was performed with the aim of correcting FSR for another estimate of intracellular (i.e., intrahepatic) Phe specific activity, i.e., Phe-derived Tyr speciflc activity in plasma. Obviously, such a calculation yields only qualitative information, since plasma Tyr specific activity cannot be used to estimate intracellular Phe specific activity in the liver or, therefore, absolute values of fibrinogen FSR for the following reasons: 1 ) Only $\sim 15-20 \%$ of plasma Tyr derives from hydroxylation of Phe $(19,20)$, the majority of its flux being accounted for by proteolysis. 2) Dilution of plasma $\left[{ }^{14} \mathrm{C}\right] \mathrm{Ty}$ specific activity reflects proteolysis occurring almost everywhere in body tissues, while Phe hydroxylation into Tyr should take place almost exclusively in liver (21). Therefore, plasma Tyr specific activity would greatly underestimate "true" intracellular Phe specific activity, which would in turn lead to overestimation of any kinetic calculation involving the use of Tyr specific activity at the denominator, as discussed extensively in Tessari et al. (15). Nevertheless, plasma $\left[{ }^{14} \mathrm{C}\right]$ or $\left[{ }^{3} \mathrm{H}\right] \mathrm{Tyr}$ specific activity may at least provide some qualitative information on the direction of the changes in the specific activity of intracellular Phe-derived metabolites.

In the two subjects in whom the $\left[{ }^{14} \mathrm{C}\right]$ Leu tracer was infused, fibrinogen-bound $\left[{ }^{14} \mathrm{C}\right]$ Leu specific activity and plasma $\left[{ }^{14} \mathrm{C}\right] \mathrm{KIC}$ specific activity, as precursor pool, were used in the calculation of FSRs (Eq. 1) (17).
Statistical analysis. The data were analyzed using the two-tailed Student $t$ test for paired data in the comparison of the glucagon versus basal periods. A $P$ value $<0.05$ was considered statistically significant. All data have been expressed as means $\pm \mathrm{SE}$.

\section{RESULTS}

The average steady-state values of plasma hormone and substrate concentrations, isotope enrichments, and specific activities in the basal and the high-glucagon period are reported in Table 1. Glucagon concentration was increased by $\sim 70 \%(P<$ 0.01 ), while insulin and C-peptide concentrations, as well as growth hormone measured in seven subjects (12), did not change significantly versus basal (Table 1).

Phe concentration did not change, but Leu concentration decreased $(P<0.01)$, as also reported previously (12). Phe specific activity increased, although not significantly $(P>0.1)$, while Leu and KIC MPEs $(n=6)$ increased $(P<0.02)$. Leu and KIC specific activities also increased slightly in the two subjects infused with $\left[{ }^{14} \mathrm{C}\right]$ Leu (Table 1). Plasma Tyr specific activity did not change significantly versus basal (Table 1). The ratio between plasma Tyr and Phe specific activities was unchanged as well $(0.21 \pm 0.05$ in the basal state, $0.21 \pm 0.03$ following glucagon). The corrected plasma Phe specific activity, calculated by multiplying plasma Phe specific activity times the ratio of KIC to Leu enrichment $(n=6)$ or specific activity $(n=2)$, also did not change after glucagon (Table 1 ).

Whole-body kinetics of both Leu and Phe have been reported previously (12); therefore, they are not presented here.

The slopes correlating the change of fibrinogen-bound Phe specific activity (as changes in disintegrations per minute per nanomole) versus time (in minutes) increased significantly after glucagon $(P<0.03)$, from $0.00039 \pm 0.00007$ to $0.00070 \pm$ 0.00018 . The $r$ correlation coefficients were $0.95 \pm 0.04$ in the basal period and $0.89 \pm 0.05$ after hyperglucagonemia.

\section{TABLE 1}

Plasma glucose, Phe, Leu, and hormone concentrations; Phe and Tyr specific activities; Phe specific activity corrected for the ratio of KIC to Leu MPE; and Leu and $\alpha$-KIC MPEs at steady state in the basal and high-glucagon period

\begin{tabular}{lcc}
\hline & Basal & Glucagon \\
\hline Glucose $(\mathrm{mg} / \mathrm{dl})$ & $87 \pm 9$ & $134 \pm 8^{*}$ \\
Insulin $(\mathrm{mU} / \mathrm{/})$ & $12 \pm 1$ & $12 \pm 1$ \\
Glucagon $(\mathrm{ng} / \mathrm{l})$ & $207 \pm 106$ & $347 \pm 129^{*}$ \\
C-peptide $(\mu \mathrm{g} / \mathrm{l})$ & $0.41 \pm 0.10$ & $0.54 \pm 0.13$ \\
Growth hormone $(\mu \mathrm{U} / \mathrm{l})$ & $1.3 \pm 0.2$ & $1.5 \pm 0.2$ \\
Phe $(\mu \mathrm{mol} / \mathrm{/})$ & $53 \pm 2$ & $52 \pm 2$ \\
Leu $(\mu \mathrm{mol} / \mathrm{/})$ & $153 \pm 6$ & $142 \pm 8^{*}$ \\
Phe specific activity (dpm/nmol) & $5.00 \pm 0.64$ & $5.19 \pm 0.64$ \\
Phe corrected specific activity & $3.93 \pm 0.52$ & $3.89 \pm 0.45$ \\
Tyr specific activity (dpm/nmol) & $0.91 \pm 0.15$ & $1.01 \pm 0.14$ \\
Leu MPE & $3.42 \pm 0.26$ & $3.84 \pm 0.26^{*}$ \\
KIC MPE & $2.64 \pm 0.20$ & $3.0 \pm 0.22^{*}$ \\
\hline
\end{tabular}

Data are means $\pm \mathrm{SD}$. The $\left[{ }^{14} \mathrm{C}\right] \mathrm{Phe}(n=7)$ and $\left[{ }^{3} \mathrm{H}\right] \mathrm{Phe}(n=2)$ specific activity values were pooled. The same was done for the corresponding Tyr specific activity values. Leu and KIC MPEs were determined in six subjects (12). In the two last subjects infused with $\left[{ }^{14} \mathrm{C}\right]$ Leu, plasma Leu and KIC specific activities were $2.56 \pm 0.27$ and $1.99 \pm 0.27 \mathrm{dpm} / \mathrm{nmol}$ in the basal period, and they increased (in both subjects) to $2.99 \pm 0.27$ and $2.04 \pm 0.3$, respectively, during glucagon infusion. ${ }^{*} P<0.02$ or less vs. basal. 
Fibrinogen FSRs calculated using plasma Phe specific activity either without or with correction are shown in Fig. 1. FSR increased significantly $(P<0.025)$, using either method of calculation, by $\sim 60-80 \%$, from $12.9 \pm 3.6$ to $21.5 \pm 6.1 \%$ per day (uncorrected specific activity) and from $16.6 \pm 4.8$ to $29.4 \pm 8.8 \%$ per day (corrected specific activity). FSR also increased, by $\sim 62 \%(P=0.046)$, using plasma Tyr specific activity as precursor pool (from $61.3 \pm 5.0$ to $99.3 \pm 24.0 \%$ per day). In the two studies using the $\left[{ }^{14} \mathrm{C}\right]$ Leu tracer, fibrinogen FSR increased by $\sim 70 \%$ on average.

\section{DISCUSSION}

This study provides evidence for an acute stimulatory effect of hyperglucagonemia on fibrinogen FSR in humans. Following $\sim 3 \mathrm{~h}$ of hyperglucagonemia, FSR was increased by $\sim 60$ to $\sim 80 \%$, depending on the precursor pool used for the calculations. This increment occurred during maintenance of insulin, C-peptide, and growth hormone concentrations at near-basal levels. The glucagon concentrations achieved during the high-rate infusion period were slightly supraphysiological (i.e., about two to three times the basal postabsorptive values); however, these concentrations can be found in insulin-deficient diabetes (10), stressed conditions (11), or exercise (22). Interestingly, fibrinogen FSR was reported to be increased in the recovery phase after exercise (23).

Although it has been suggested that fibrinogen synthesis may be stimulated by glucagon (24), no direct evidence has been reported in vivo so far. In the perfused rat liver in vitro, glucagon increased fibrinogen secretion (25). In cultured human hepatocytes, glucagon increased the synthesis of some acute-phase proteins (26), although the effect on fibrinogen was not reported. In vivo infusion of glucagon for 24 $\mathrm{h}$ to double fasting values in normal volunteers increased fibrinogen concentration by $\sim 30 \%$ (27). Thus, physiological hyperglucagonemia in prolonged infusions can increase plasma fibrinogen concentration. In that study (27), however, no precursor-product kinetic study was performed. Conversely, in our study, we did not measure plasma fibrinogen concentration before and after glucagon. However, should any change have occurred, it should have been in the direction of an increase that, combined with the stimulated FSR, would lead to an even greater effect on absolute secretion/synthetic rate than that evidenced only by FSR.

Among other variables that could have affected our results, hyperglycemia should also be considered. Glucose has been suggested to stimulate the coagulative cascade in vivo (28). This in turn may activate fibrinogen synthesis and secretion (29). A correlation between blood glucose concentrations and fibrinogen levels in diabetes has been found in large epidemiological studies (30). Thus, the glucagoninduced hyperglycemia in this study (from 87 to $134 \mathrm{mg} / \mathrm{dl}$ ) (Table 1) might represent an independent concurrent stimulus for fibrinogen FSR. Obviously, such a possibility needs to be specifically investigated.

Strictly speaking, the precursor-product method of measuring fractional protein synthesis cannot distinguish between release into plasma of previously formed molecules, increased synthesis, or both. Thus, we use the term fractional secretion rather than synthetic rate. Whatever the mechanism, however, our data suggest that glucagon increased the release into plasma of newly formed fibrinogen molecules.

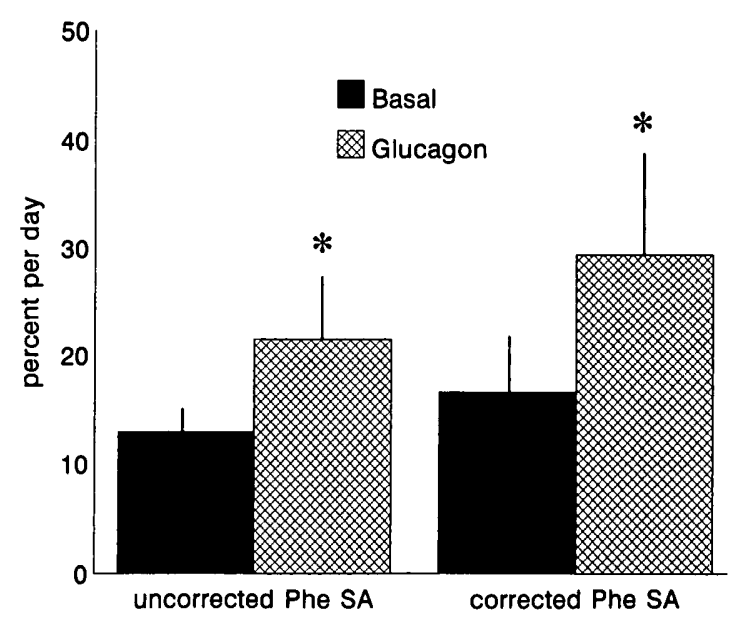

FIG. 1. Fibrinogen FSR (as percentage of pool per day) before and after hyperglucagonemia, calculated using either plasma Phe specific activity or the corrected value as precursor pool (Eq. 1) (see METHODS and RESULTS). $* P<0.025$ vs. basal.

The accurate estimation of FSR of a liver secretory protein requires knowledge of the intrahepatic precursor pool. Such a pool may be indirectly reflected either by the tracer specific activity and enrichment attained in a short-lived hepatic protein at steady state (i.e., in VLDL apolipoprotein B [Apo B] 100) (31) or by other indirect methods, such as KIC labeling in plasma following Leu tracer infusion (32-34). Indeed, plasma KIC enrichment and specific activity have been shown to be very close to those of VLDL-Apo B 100-bound Leu at steadystate $(31,34)$. In our study, because of the short-term experimental periods, isolation and measurement of Phe specific activity in VLDL-Apo B were not performed. At variance with Leu, Phe does not have any derived compound analogous to $\mathrm{KIC}$ that is measurable in plasma (21). However, in the attempt to obtain at least an indirect estimate of intracellular/intrahepatic Phe specific activity, we have recalculated fibrinogen FSR using a Phe specific activity value corrected for the ratio between KIC and Leu enrichment (or specific activity) determined in each patient, as suggested by Millward et al. (18). This calculation assumes that the same dilution between intracellular (i.e., KIC) and plasma Leu specific activity also occurs with regard to Phe specific activity (18). In the fasting state, the fibrinogen FSR values calculated with such a correction were in the range of previous data obtained with Leu tracers (Table 2) $(8,9,23)$, thus providing indirect support for the validity of this calculation. Furthermore, the FSR values were $\sim 30$ greater, in both the basal and the glucagon infusion period, than those calculated using plasma Phe specific activity; this agrees with the conclusion of a recent paper in which FSRs of secreted pancreatic enzymes were measured with both Leu and Phe tracers (35). Following glucagon, FSR increased by nearly the same magnitude as that calculated using plasma specific activity (Fig. 1). To obtain further insight into intrahepatic Phe specific activity, we have also determined plasma Tyr specific activity, which may reflect, at least in part and only from a qualitative point of view, possible changes in intrahepatic Phe specific activity following glucagon $(15,21)$. The ratio between plasma Tyr and Phe specific activities did not change during hyperglucagonemia (see RESULTS), suggesting no disequilibrium between the specific activities of plasma and intracellular Phe-related compounds 
following glucagon. Consequently, fibrinogen FSR calculated using plasma Tyr specific activity increased by the same percentage as that observed using the two other calculation methods (see RESULTS), although these absolute values are meaningless, as discussed above. It should also be considered that whole-body as well as intrahepatic pools of free Phe are small (i.e., between 20 and $35 \%$ of those of Leu) (19,36,37), suggesting a rapid equilibration of Phe tracers between the extracellular and intracellular pools. Therefore, despite the limitation of the Phe tracer technique used here, these data are highly suggestive of an acute stimulatory effect of glucagon on fibrinogen FSR. This conclusion is supported by the data from the two subjects infused with $\left[{ }^{14} \mathrm{C}\right] \mathrm{Leu}$, who showed a consistent stimulation (by $~ 70 \%$ ) of fibrinogen FSR by glucagon. Whether chronic hyperglucagonemia is also responsible for the increased fibrinogen concentrations observed in specific pathological conditions, such as uncontrolled diabetes $(4,7)$, needs to be investigated.

In conclusion, this study suggests that isolated hyperglucagonemia acutely stimulates fibrinogen FSR in vivo in humans and that it might be implicated in the genesis of hyperfibrinogemia under conditions when glucagon concentrations are elevated as well.

\section{REFERENCES}

1. Gordon AH: The acute phase plasma proteins. In Plasma Protein Turnover. Bianchi R, Mariani G, Mcfarlane AS, Eds. Baltimore, MD, Univ. Park Press, 1976, p. 381-394

2. Kannel WB, Wolf PA, Castelli WP, D'Agostino RB: Fibrinogen and risk of cardiovascular disease: the Framingham Study. JAMA 258:1183-1186, 1987

3. Ernst E: Fibrinogen: an independent risk factor for cardiovascular disease. $\mathrm{Br}$ Med J 303:596-597, 1991

4. Ceriello A, Taboga C, Giacomello R, Falleti E, De Stasio G, Motz E, Lizzio S, Gonano F, Bartoli E: Fibrinogen plasma levels as a marker of thrombin activation in diabetes. Diabetes 43:430-342, 1994

5. Ermst E, Matray A, Schmolz C, Magyarosy I: Dose-effect relationship between smoking and blood rheology. Br J Haematol 65:485-491, 1987

6. Morimoto R, Tissieres A, Georgopoulos C (Eds.): Stress Proteins in Biology and Medicine. Cold Spring Harbor, NY, Cold Spring Harbor Laboratory Press, 1990

7. Ganda OP, Arkin CF: Hyperfibrinogenia: an important risk factor for vascular complications in diabetes. Diabetes Care 15:1245-1250, 1992

8. De Feo P, Gaisano MG, Haymond MW: Differential effects of insulin deficiency on albumin and fibrinogen synthesis in humans. J Clin Invest 88 : 833-840, 1991

9. De Feo P, Volpi E, Lucidi P, Cruciani G, Reboldi G, Siepi D, Mannarino E, Santeusanio F, Brunetti P, Bolli G: Physiological increments in plasma insulin concentrations have selective and different effects on synthesis of hepatic proteins in normal humans. Diabetes 42:995-1002, 1993

10. Unger RH: Glucagon and insulin:glucagon ratio in diabetes and the other catabolic illness. Diabetes 20:834-838, 1972

11. Russel RCG, Walker CJ, Bloom SR: Hyperglucagonemia in the surgical patient. Br Med $J$ 1:10-12, 1975

12. Tessari P, Inchiostro S, Barazzoni R, Zanetti M, Vettore M, Biolo G, Iori E, Kiwanuka E, Tiengo A: Hyperglucagonemia stimulates phenylalanine oxidation in man. Diabetes 45:463-470, 1996

13. Tessari P, Inchiostro S, Vettore M, Sabadin L, Biolo G: A fast HPLC method for the measurement of plasma concentration and specific activity of phenylalanine. Clin Biochem 24:425-428, 1991

14. Nissen SL, Van Huysen C, Haymond MW: Measurement of branched-chain amino acids and branched-chain $\alpha$-ketoacids in plasma by high-performance liquid chromatography. J Chromatogr 232:170-175, 1982

15. Tessari P, Barazzoni R, Zanetti M, Vettore M, Normand S, Bruttomesso D, Beaufrere B: Protein degradation and synthesis measured with multiple amino acid tracers in vivo. Am J Physiol 271:E733-E741, 1996
16. Schwenk WF, Berg PJ, Beaufrere B, Miles JM, Haymond MW: Use of t-butyldimethylsilylation in the GC/MS analysis of physiologic compounds found in plasma using electron impact ionization. Anal Biochem 141:101-109, 1984

17. Horber FF, Kahl J, Lecavalier L, Krom B, Haymond MW: Determination of leucine and $\alpha$-ketoisocaproic acid concentrations and specific activity in plasma and of leucine specific activity in proteins using high performance liquid chromatography. J Chromatogr 495:81-94, 1989

18. Millward DJ, Price GM, Pacy PJH, Halliday D: Whole body protein turnover: what can we measure with confidence? Proc Nutr Soc 50:195-214, 1991

19. Clarke JTR, Bier BM: The conversion of phenylalanine to tyrosine in man: direct measurement by continuous intravenous tracer infusion of $L$-[ring$\left.{ }^{2} \mathrm{H}_{5}\right]$ phenylalanine and $\mathrm{L}-\left[1-{ }^{13} \mathrm{C}\right]$ tyrosine in the postabsorptive state. Metabolism 31:999-1005, 1982

20. Thompson GN, Pacy PJ, Merritt H, Ford GC, Read MA, Cheng KN, Halliday $\mathrm{D}$ : Rapid measurement of whole-body and forearm protein turnover using a $\left[{ }^{2} \mathrm{H}_{5}\right]$ phenylalanine model. Am J Physiol 256:E631-E639, 1989

21. Rosenberg LE, Scriver CR: Disorders of amino acid metabolism. In Metabolic Control and Disease. Bondy PK, Rosenberg LE, Eds. Philadelphia, Saunders, 1980 , p. $707-710$

22. Lickley HLA, Kemmer FW, Wasserman DH, Vranic M: Glucagon and its relationship to other glucoregulatory hormones in exercise and stress in normal and diabetic subjects. In Glucagon. Vol II. Lefèbvre PJ, Ed. Berlin, Springer, 1983, p. $297-350$

23. Carraro F, Hartl WH, Stuart CA, Layman DK, Jahoor F, Wolfe RR: Whole-body and plasma protein synthesis in exercise and recovery in human subjects. $A m$ J Physiol 258:E821-E831, 1990

24. McMillan DE: Clotting disorders in diabetes. In International Textbook of Diabetes Mellitus. Alberti KGMM, DeFronzo RA, Keen H, Zinmet P, Eds. New York, Wiley, 1992, p. 1447-1457

25. Miller LL, Griffin EE: Regulation of net biosynthesis of albumin, fibrinogen, $\alpha-1$ acid glycoprotein, $\alpha-2$ (acute phase) globulin and aptoglobin by direct action of hormones on the isolated perfused liver. In Biochemical Actions of Hormones. Litwak G, Ed. New York, Academic, 1975, p. 159-186

26. O'Riodain MG, Ross JA, Fearon KC, Maingay J, Farouk M, Garden OJ, Carter DC: Insulin and counterregulatory hormones influence acute-phase protein production in human hepatocytes. Am J Physiol 269:E323-E330, 1995

27. Rosenfeld BA, Faraday N, Campbell D, Dise K, Bell W, Goldschnidt P: Hemostatic effects of stress hormone infusion. Anesthesiology 81:1116-1126, 1994

28. Ceriello A, Quatraro A, Marchi E, Barbanti M, Dello Ruddo P, Lefebvre PJ: The role of hyperglycemia-induced alterations of antithrombin III and factor X activation in the thrombin hyperactivity of diabetes mellitus. Diabet Med $7: 343-348,1990$

29. Ritchie DG, Levy BA, Adams MA, Fuller GM: Regulation of fibrinogen synthesis by plasmin-derived fragments of fibrinogen and fibrin: an indirect feedback pathway. Proc Natl Acad Sci USA 79:1530-1534, 1982

30. Kannel WB, McGee DL: Diabetes and cardiovascular disease: the Framingham Study. JAMA 241:2035-2038, 1979

31. Parhofer KG, Hugh P, Barrett R, Bier DM, Schonfeld G: Determination of kinetic parameters of apolipoprotein $B$ metabolism using amino acids labeled with stable isotopes. J Lipid Res 32:1311-1323, 1991

32. Cryer DR, Matsushima T, Marsh JB, Yudkoff M, Coates PM, Cortner JA: Direct measurement of apolipoprotein B synthesis in human very low density lipoprotein using stable isotopes and mass spectrometry. $J$ Lipid Res 27:508-516, 1986

33. Wolfe RR, Goodenaugh RD, Wolfe MH, Royle GT, Nadel ER: Isotopic analysis of leucine and urea metabolism in exercising humans. J Appl Physiol 52:459-466, 1982

34. Schwenk WF, Beaufrere B, Haymond MW: Use of reciprocal pool specific activities to model leucine metabolism in man. Am J Physiol 249:E646-E650, 1985

35. Bennet WM, O'Keefe JD, Haymond MW: Comparison of precursor pools with leucine, $\alpha$-ketoisocaproate, and phenylalanine tracers used to measure splanchnic protein synthesis in man. Metabolism 42:691-695, 1993

36. Waterlow JC, Garlick PJ, Millward DJ: Free amino acids. In Protein Turnover in Mammalian Tissues and in the Whole Body. Waterlow JC, Garlick PJ, Millward DJ, Eds. New York, North Holland Publishing, p. 117-176

37. Cobelli C, Saccomani MP, Tessari P, Biolo G, Luzi L, Matthews DE: Compartmental model of leucine kinetics in humans. Am J Physiol 261:E539-E550, 1991 